\title{
Loudness Perception in the Domestic Cat: Reaction Time Estimates of Equal Loudness Contours and Recruitment Effects
}

\author{
Bradford J. May, ${ }^{1}$ Nicole Little, ${ }^{1}$ and Stephanie Saylor ${ }^{1}$ \\ ${ }^{1}$ Center for Hearing and Balance, Department of Otolaryngology—Head and Neck Surgery, Johns Hopkins University School of \\ Medicine, Traylor Research Building, Room 521, 720 Rutland Avenue, Baltimore, MD 21205, USA
}

Received: 14 November 2008; Accepted: 20 January 2009; Online publication: 7 February 2009

\begin{abstract}
The domestic cat is the primary physiological model of loudness coding and recruitment. At present, there are no published descriptions of loudness perception in this species. This study used a reaction time task to characterize loudness perception in six behaviorally trained cats. The psychophysical approach was based on the assumption that sounds of equal loudness elicit responses of equal latency. The resulting equal latency contours reproduced well-known features of human equal loudness contours. At the completion of normal baseline measures, the cats were exposed to intense sound to investigate the behavioral correlates of loudness recruitment, the abnormally rapid growth of loudness that is commonly associated with hearing loss. Observed recruitment effects were similar in magnitude to those that have been reported in hearing-impaired humans. Linear hearing aid amplification is known to improve speech intelligibility but also exacerbate recruitment in impaired listeners. The effects of speech spectra and amplification on recruitment were explored by measuring the growth of loudness for natural and amplified vowels before and after sound exposure. Vowels produced more recruitment than tones, and the effect was exacerbated by the selective amplification of formant structure. These findings support the adequacy of the domestic cat as a model system for future investigations of the auditory processes that underlie loudness perception, recruitment, and hearing aid design.
\end{abstract}

Correspondence to: Bradford J. May · Center for Hearing and Balance, Department of Otolaryngology-Head and Neck Surgery · Johns Hopkins University School of Medicine · Traylor Research Building, Room 521, 720 Rutland Avenue, Baltimore, MD 21205, USA Telephone: +1-410-6141878; fax: +1-410-9551299; email: bmay@jhu. edu
Keywords: auditory reaction time, loudness estimation, sound exposure, sensorineural hearing loss

\section{INTRODUCTION}

Although loudness is related to the physical characteristics of sounds, especially their energy, it is a psychological attribute that is strongly shaped by how the energy is transduced, filtered, and integrated over time (Plack and Carlyon 1995). In studies of human perception, methods for the quantification of subjective loudness are straightforward. Subjects can be asked to rank a stimulus on a perceptual scale (Stevens and Guirao 1963), or to match it to a reference sound (Fletcher and Munson 1933). Neither approach translates well to common animal behavioral methodologies. Consequently, psychophysicists have sought tractable measures of loudness in the form of reaction time (RT) matching procedures (Miller et al. 1969). A broad assumption of these paradigms is that louder sounds generate shorter response latencies. By corollary, sounds with the same RT are interpreted to be equally loud. There is ample evidence that this metric is a useful tool for gauging loudness percepts in human subjects, for whom it is possible to make direct comparisons of conventional loudness estimates and RT measures (Marshall and Brandt 1980; Pfingst et al. 1975) or to replicate well-established loudness effects (Arieh and Marks 2003; Florentine et al. 2004; Wagner et al. 2004).

Because the physical and psychological dimensions of sound magnitude are distinct from one another, physiological studies are constrained by a lack of 
psychophysical assessments of loudness in traditional animal models. For example, although much work has been directed toward the neural coding of sound intensity in domestic cats (Ehret and Merzenich 1988; Evans 1978; Heinz et al. 2005; Heinz and Young 2004; Palmer and Evans 1982), there are currently no behavioral descriptions of loudness perception. The present study was designed to amend that omission by estimating the loudness of pure tones from the RT of responses in a detection task. Equal latency contours were derived from these data for comparison with human equal loudness contours. A related issue with pressing clinical significance is the abnormally rapid growth of loudness, or recruitment, that accompanies sensorineural hearing loss (Davis and Goodman 1966). This phenomenon was explored by comparing RT measures before and after hearing was damaged by sound exposure. Finally, the potential consequences of hearing aid amplification were investigated by characterizing the loudness of normal and amplified vowels in cats with noise-induced recruitment.

\section{METHODS}

All methods were approved by the Animal Care and Use Committee of The Johns Hopkins University School of Medicine.

\section{Subjects}

Six male domestic cats were used as subjects. They were procured from Liberty Labs (Liberty, NJ, USA) and housed in individual cages within the laboratory's dedicated animal facilities. The cats were fed a restricted diet that combined meat paste rewards during experimental sessions with dry cat food after each session. They were given partial rations on work days to motivate behavior and full rations when no experimental sessions were scheduled the next day (e.g., Fridays and Saturdays). Each cat was routinely examined by laboratory and veterinary staff to ensure normal growth, good general health, and clean external ears.

\section{Behavioral apparatus}

Experiments were conducted inside a double-walled sound chamber. To control acoustic reflections, the interior walls of the chamber were treated with 3-in. thick $(7.6 \mathrm{~cm})$ sound-attenuating foam. The subject was positioned at a fixed location within the sound field by an operant platform that provided a mounting surface for the response lever and food delivery tube (Fig. 1). Auditory stimuli were presented from a single loudspeaker that was placed in front of and slightly above the platform at a distance of $1 \mathrm{~m}$. Head movements were restricted by a loose canvas body restraint bag and a rigid collar. Although head and pinna movements were not eliminated by the restraint system, the cats adopted a stable alert posture during the interval preceding tone presentations to optimize performance.

\section{Tone detection task}

Loudness perception was estimated from RT in a tone detection task (Fig. 1). The subject initiated a behavioral cycle by pressing down on the lever and holding the response for a time interval that varied from 5 to $10 \mathrm{~s}$. The cycle advanced to a trial state if the subject maintained the observing response for the duration of the variable hold period.

The onset of a $250-\mathrm{ms}$ tone burst (10-ms rise/fall time) signaled the transition to a detection trial. The stimulus cycled on and off in 1-s periods. The subject received a food reward by releasing the lever before the termination of the 2-s trial window. The RT measure was based on the latency of the lever release relative to the onset of the initial tone burst. Reaction times greater than 1 s (i.e., after the second tone burst) were rare and were not included in the analysis of loudness effects.

The subject produced a time out interval by releasing the lever during the variable hold interval, or by failing to release the lever during the detection trial. Cats avoided response errors because the resulting 5-s interruption of the behavioral cycle delayed the availability of the food reward.

Stimulus levels were varied to sample loudness effects across the dynamic range of hearing. Consequently, at near-threshold sound levels, the percentage of detection responses was inflated by chance responding. Catch trials were presented on $25 \%$ of all trials to monitor the probability of false positive

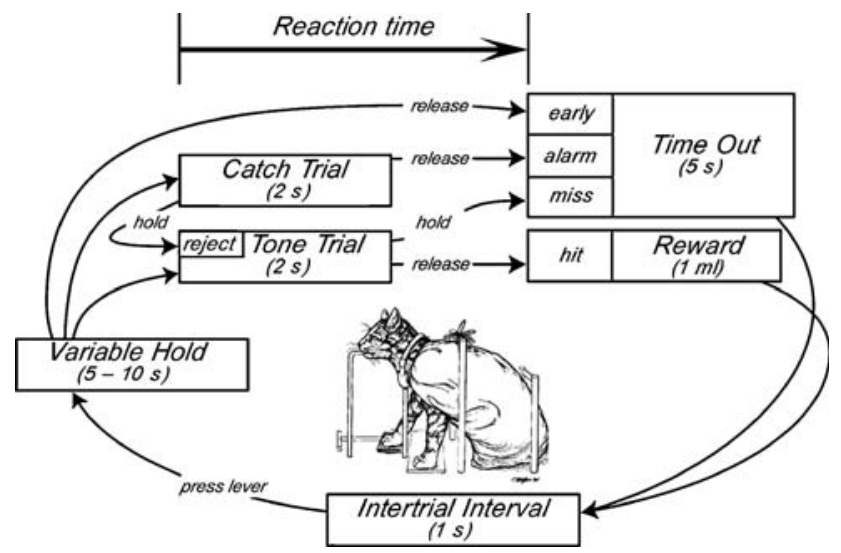

FIG. 1. Contingencies of reinforcement for the tone detection task. Inset shows the behavioral testing platform and restraint system. 
responses. Catch trials shared all of the timing properties of detection trials but did not include tone bursts. The behavioral cycle advanced immediately to a trial state if the subject rejected the catch trial by continuing to hold down the lever for $2 \mathrm{~s}$. As in other error responses, releasing the lever during the catch trial (false alarm) produced a time out.

The amount of the reward was adjusted on an individual basis to ensure motivated behavior throughout a 45-min testing session. Most cats received $1 \mathrm{ml}$ of meat paste for every correct tone detection. The amount of trials completed in the daily sessions varied because cats controlled the pace of the experiment. Typically, 150-225 trials were distributed across tone bursts of the same frequency but different levels (Fig. 2A). Presentation levels varied pseudorandomly from near the detection threshold to clearly above threshold. This procedure produced a daily psychometric function that reflected the subject's performance with sufficient accuracy to direct ongoing adjustments in testing conditions. Loudness estimates were determined by combining the results of daily sessions over weeks of stable performance. A minimum of 400 trials was
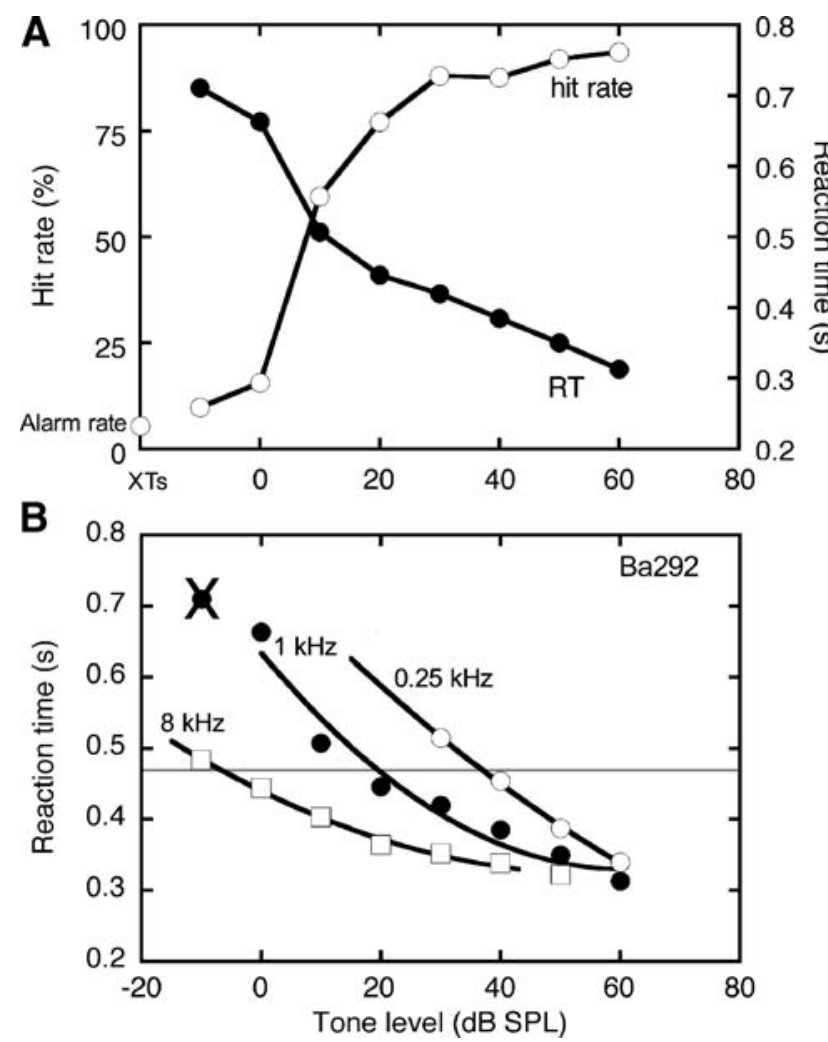

FIG. 2. Typical responses in the tone detection task (cat Ba292). A Psychometric functions for tests with $1-\mathrm{kHz}$ tones. B Effects of frequency on RT-level functions. Actual RTs (symbols) have been fitted with second-order polynomials (lines). The data at $-10 \mathrm{~dB}$ SPL are not included in the $1-\mathrm{kHz}$ fit because the stimulus condition elicited a hit rate that was not significantly different from the subject's false alarm rate. collected at each tone level, but in most instances, several thousand trials were performed.

Behavioral audiograms were derived to confirm that each cat showed normal hearing sensitivity prior to sound exposure and significant hearing loss after exposure. Threshold measures were based on the signal detection criterion $d^{\prime}=1$ (Green 1960). This statistic was calculated from the response probabilities for detection and catch trials, as shown in Eq. 1:

$$
d^{\prime}=z\left(P_{\text {hit }}\right)-z\left(P_{\text {false alarm }}\right),
$$

where $z\left(P_{h i t}\right)$ is the standardized probability ( $z$ score) of correct responses at each stimulus level and $z\left(P_{\text {false alarm }}\right)$ is the standardized probability ( $z$ score) of false alarms. When psychometric functions relating $d^{\prime}$ scores to tone level did not include stimulus values corresponding to threshold, the predicted level was derived by linear interpolation between two values bracketing threshold.

\section{Reaction time matching}

The results of loudness-matching paradigms are typically expressed in phons, which is a unit of perceptual magnitude that is defined as the sound pressure level (SPL) of a $1-\mathrm{kHz}$ tone with equivalent loudness. For example, a $0.125-\mathrm{kHz}$ tone might require an SPL of $70 \mathrm{~dB}$ to match the loudness of a $1-\mathrm{kHz}$ tone with an SPL of $40 \mathrm{~dB}$. Thus, at 70-dB SPL, the $0.125-\mathrm{kHz}$ tone has a loudness level of 40 phons.

In the present study, loudness levels in phons were calculated by matching median RTs across tone frequency and level. This process is illustrated in Figure 2. The three RT functions were obtained for frequencies of $0.25,1$, and $8 \mathrm{kHz}$. Each dataset has been fitted with a second-order polynomial. Criterion latencies were derived from the $1-\mathrm{kHz}$ polynomial fit. For this cat (Ba292), the fit produced an RT of $466 \mathrm{~ms}$ at $20 \mathrm{~dB}$ SPL. Consequently, SPLs that evoked RTs of $466 \mathrm{~ms}$ at other frequencies were assigned a loudness level of 20 phons. The 0.25 - and $8-\mathrm{kHz}$ tones led to the criterion RT at 37 and $-6 \mathrm{~dB}$ SPL, respectively.

The process of loudness matching assumes that statistical distributions of RT are well governed by SPL. Representative distributions in Figure 3 show a systematic decrease in median RTs with increasing stimulus level. These data were obtained with 1-kHz tones before sound exposure (Ba292 and Pe409), or after sound exposure (Lu016). Reliable performance was confirmed by the high detection score and tight cluster of RTs at higher tone levels (lower panels). Catch trials elicited low false alarm rates and randomly distributed RTs (upper panels). On tone presentations that fell below threshold, for example, the post-exposure presentations of 
A. Cat: Ba292, pre-exposure
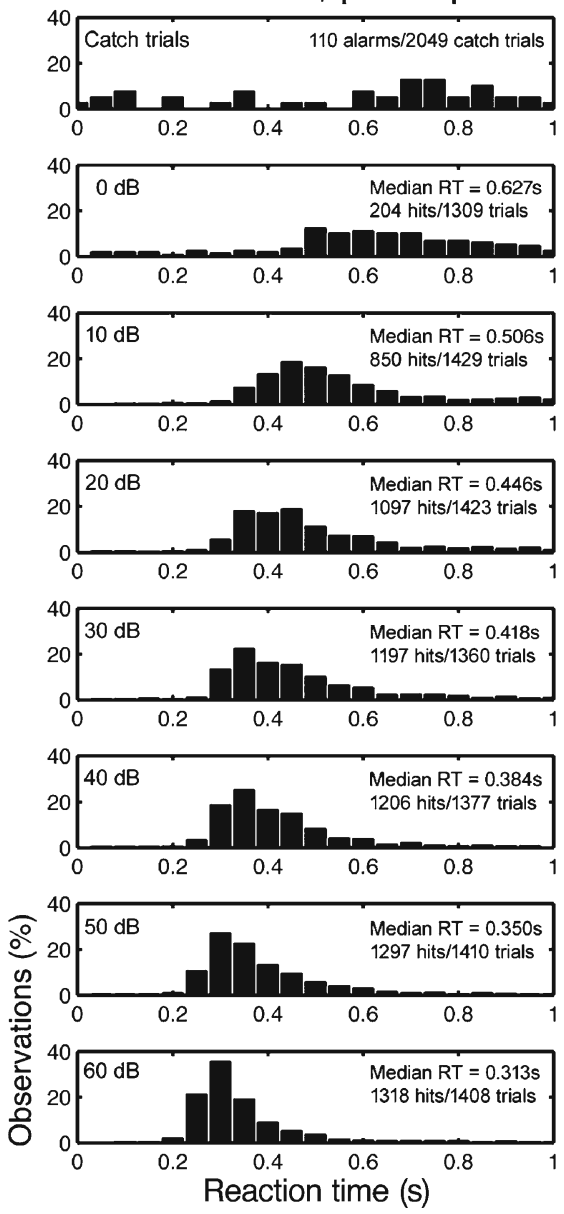

B. Cat: Pe409, pre-exposure
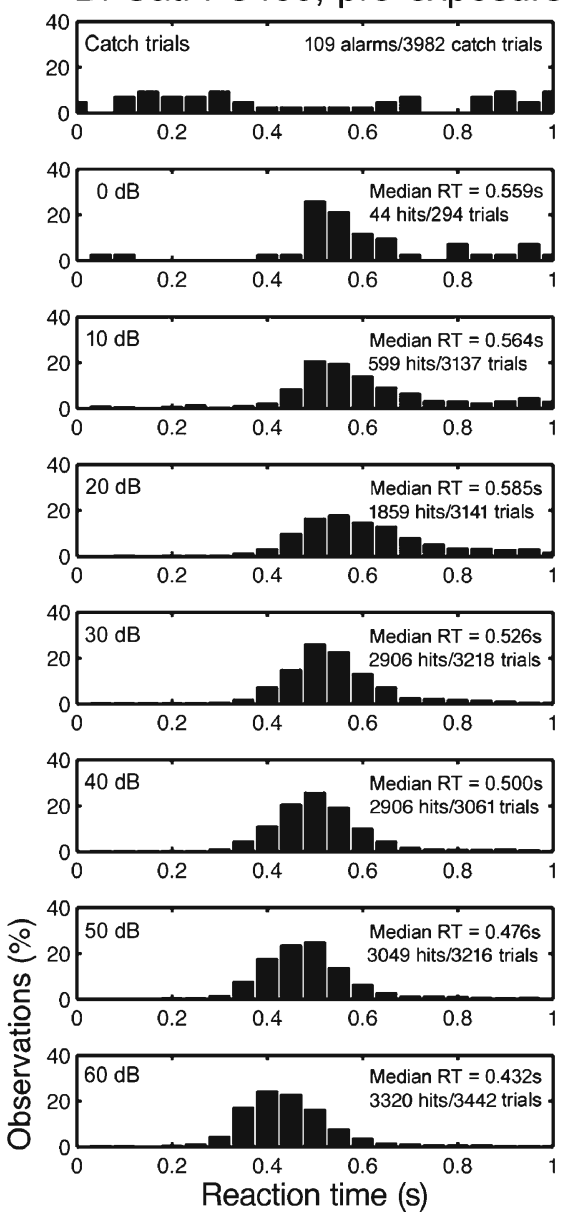

C. Cat: Lu016, post-exposure
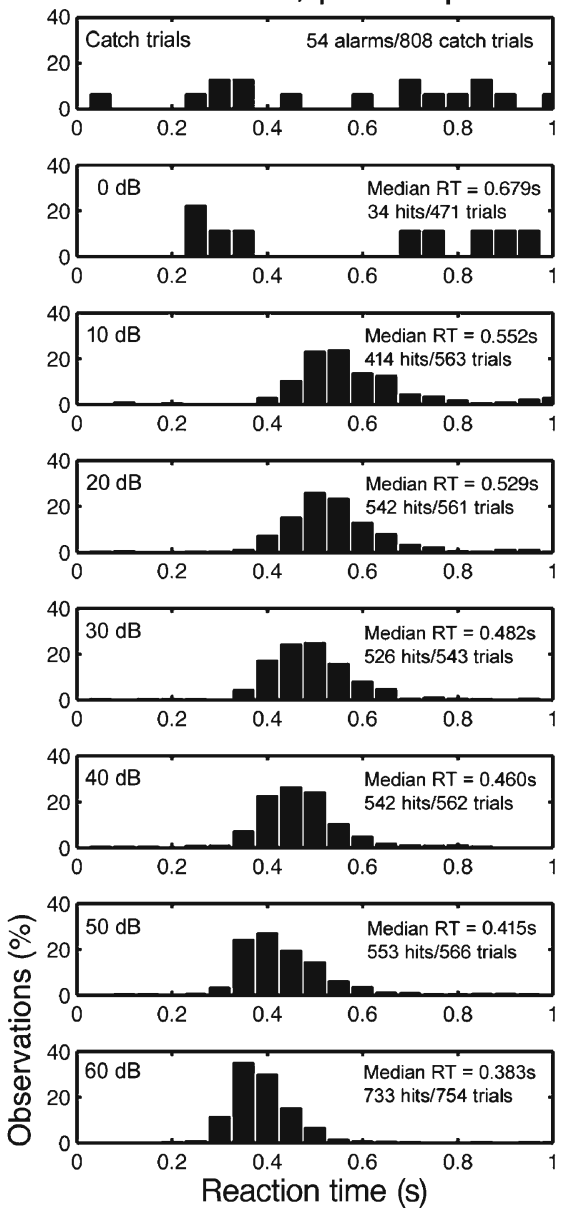

FIG. 3. Effects of SPL on the reaction time $(R T)$ distributions that were produced by $1-\mathrm{kHz}$ tones. Presentation level increases from upper to lower panels. Responses to catch trials are shown in the uppermost panels. A, B Pre-exposure data for cats Ba292 and Pe409. C Post-exposure data for cat Lu016.

$0 \mathrm{~dB}$ SPL tones to cat Lu016, the probability of detection approached chance and the RT distribution expanded. The polynomial fits used in loudness estimation were based only on suprathreshold stimuli, as defined by $d^{\prime}$ values greater than 1 and a clear peak in the RT distribution. These data raise an important qualification for RT-based measures. They are prone to error when the analysis includes near-threshold levels.

Close inspection of the statistical distributions in Figure 3 reveals another potential limitation of RTbased paradigms. Median values exhibited consistent inter-subject differences. This issue was addressed by the analysis that is summarized in Figure 4. Each pair of plots in Figure 4A compares the 1- and 4-kHz RT functions of the same cat. Three subjects were selected to illustrate extremes in RT. Cat Pe409 displayed the slowest responses, while cat Ba292 responded rapidly. If a cat was a slow or rapid responder, it displayed those tendencies at all frequencies. Therefore, as shown in Figure 4B, intersubject differences were reduced after RTs were translated to loudness level estimates because these measures were derived from the subject's own $1-\mathrm{kHz}$ latencies.

\section{Sound exposure}

Recruitment effects were evaluated in four of the cats by inducing sensorineural hearing loss with an intense sound exposure. The methods for exposure were the same as those used in previous electrophysiological studies of loudness recruitment in domestic cats (Heinz and Young 2004). The exposure stimulus had a $50-\mathrm{Hz}$ bandwidth and center frequency of $2 \mathrm{kHz}$. The level of exposure was $109 \mathrm{~dB}$ SPL. The cats were anesthetized with xylazine/ketamine during the 4-h exposure. Although all cats returned to behavioral testing within a few days of the exposure, post-exposure data are limited to the period of stable performance that was observed months after the exposure. By that time, subjects had fully recovered from temporary threshold shifts. 


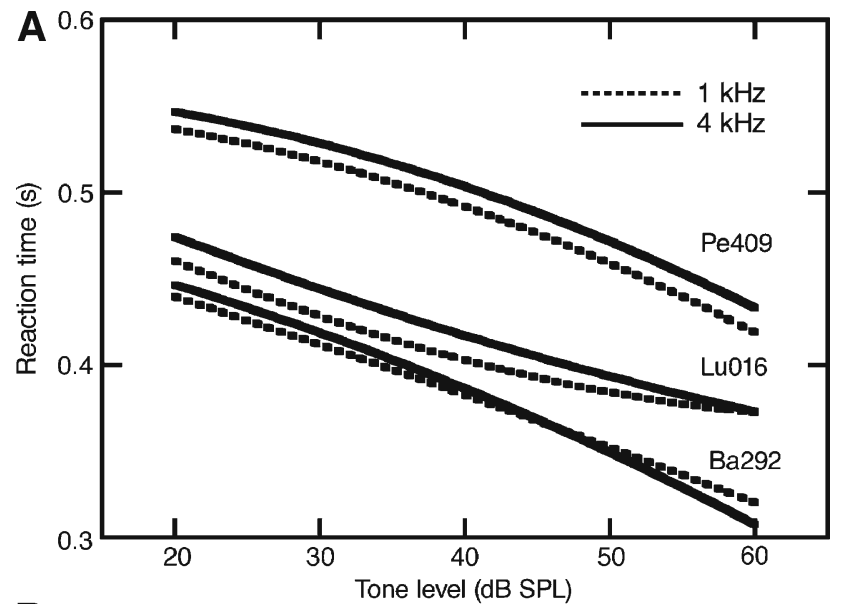

B

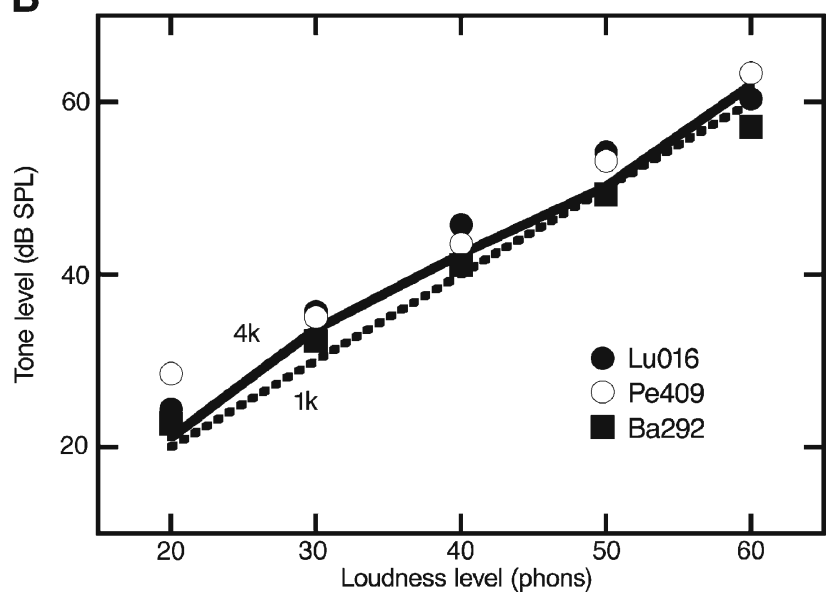

FIG. 4. Individual differences in RT data. A RT-level functions obtained from three cats at $1 \mathrm{kHz}$ (dashed lines) and $4 \mathrm{kHz}$ (solid lines). B Growth of loudness functions (GOLFs) for the three cats (symbols) and the average of six cats (lines). Reaction times were translated to units of loudness (phons) based on individualized response latencies (see text).

When previous electrophysiological experiments applied this sound exposure procedure to cats from the same supplier (Heinz and Young 2004; Miller et al. 1997; Schilling et al. 1998), single-unit activity in the auditory nerve and ventral cochlear nucleus showed elevated thresholds and broad frequency tuning at frequencies from 0.5 to $4 \mathrm{kHz}$. Hearing loss ranged from mild (threshold shifts of $25-30 \mathrm{~dB}$ ) to moderate (threshold shifts of $45-50 \mathrm{~dB}$ ), with the extent of hearing loss presumably determined by individual differences in susceptibility to acoustic trauma (Maison and Liberman 2000).

The mean pre-exposure hearing thresholds of all six cats and the mean post-exposure thresholds of four sound-exposed cats are summarized in Figure 5. Prior to exposure, absolute thresholds were approximately $5 \mathrm{~dB}$ above average values from six other psychophysical studies of domestic cats (labeled "Other" in Fig. 5A). In part, this slight disparity reflects differences in the contingencies of reinforcement between the studies, which in the present study were optimized for the collection of suprathreshold RT data. The discrepancy between the present data and previous threshold measures was largest at low frequencies. This characteristic of hearing in Liberty Labs cats has been noted in previous electrophysiological studies (Miller et al. 1997). The best neural thresholds taken from those experiments correspond closely with the behavioral thresholds of our subjects.

After sound exposure, the subjects showed an average threshold elevation of $20 \mathrm{~dB}$ at frequencies from 2 to $4 \mathrm{kHz}$ (Fig. 5B). These shifts fell within the mild hearing loss category that was reported when the same exposure method was used in previous electrophysiological studies of noise-induced hearing loss (Heinz et al. 2005; Miller et al. 1997, 1999; Schilling et al. 1998). Although the magnitude of hearing loss was
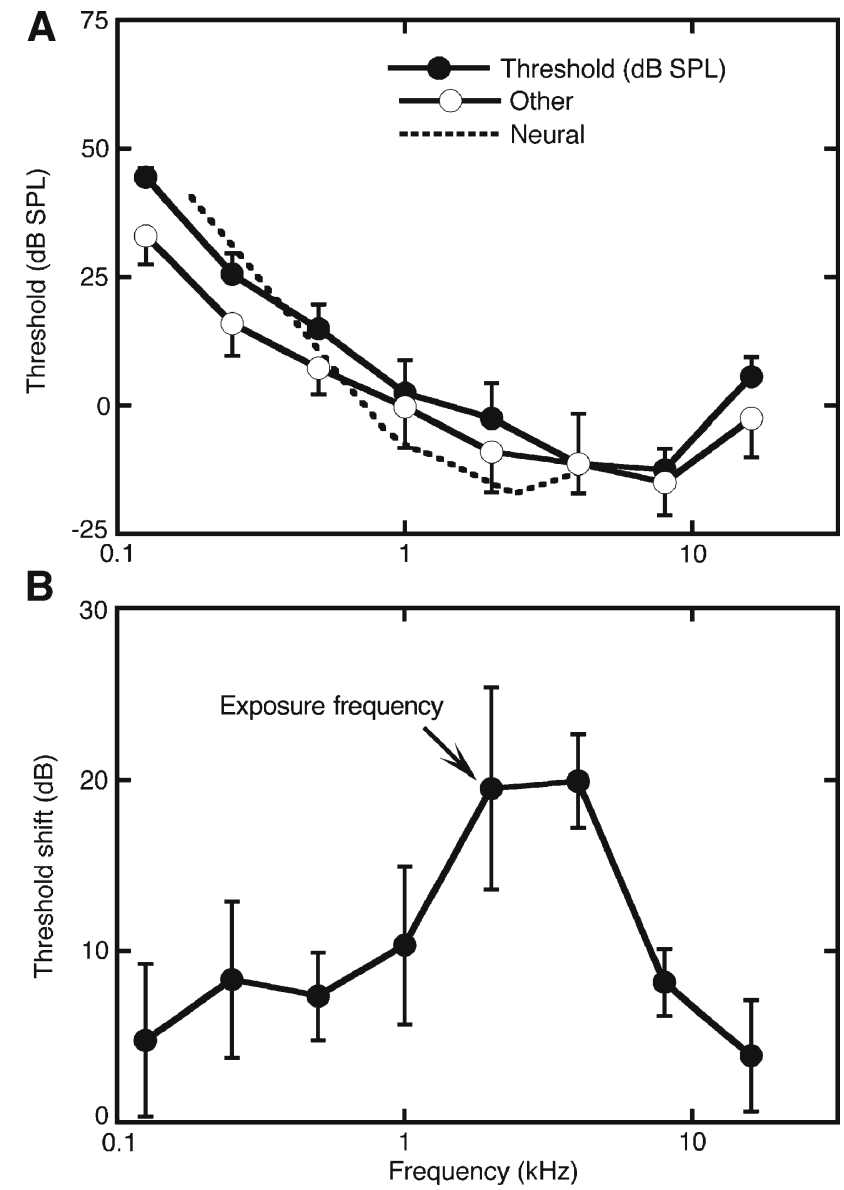

FIG. 5. Pre- and post-exposure hearing sensitivity of the behavioral cats. A Average detection threshold ( \pm SEM) of six cats as a function of tone frequency. For comparison, average thresholds $( \pm$ SEM) are shown for six independent behavioral studies (Other), as reported by Fay (1995). Best neural thresholds (Neural) are also provided for cats that were procured from the same supplier (Liberty Labs). B Permanent threshold shifts in four behavioral cats that were exposed for $4 \mathrm{~h}$ to a narrow band of noise at a level of $109 \mathrm{~dB}$ SPL. The center frequency of the noise band was $2 \mathrm{kHz}$ (arrow). 
relatively small in comparison to studies of human impairment, it was sufficient to induce recruitment without risking a breakdown of behavioral performance. It had been noted in our previous unpublished experiments that cats with larger threshold shifts do not perform well when tested at high SPLs. Those observations motivated the present behavioral analysis.

\section{Vowel stimuli}

Two sound-exposed cats (Lu016 and Pe409) were tested with vowel sounds to investigate the effects of speech amplification on loudness recruitment. Previous studies have proposed frequency-shaped amplification strategies to restore the neural representation of speech in damaged ears (Miller et al. 1999; Schilling et al. 1998). The rationale behind that approach was to reduce the dominant effect of lowfrequency vowel formants by selectively amplifying the energy of high-frequency formants. This "contrastenhanced frequency shaping" (CEFS) is illustrated by the vowel spectra in Figure 6.

Continuous spectra are shown in this figure to emphasize high-frequency differences in the vowel shapes. In fact, the stimuli were harmonic complexes with a fundamental frequency of $0.1 \mathrm{kHz}$ and formant frequencies of $0.5,1.7$, and $2.5 \mathrm{kHz}$ (Klatt and Klatt 1990). These formants are found in the natural English vowel $/ \varepsilon /$, as in bet. For convenience, references to this synthetic stimulus use the term naturally shaped (NS) vowel.

The CEFS vowel had an identical formant structure but was high-pass-filtered using a digital filter with a transition slope greater than $160 \mathrm{~dB} /$ decade and less than $5 \mathrm{~dB}$ of passband ripple. The cut-off frequency of the filter was matched to the second formant frequency to boost energy at all but the first formant

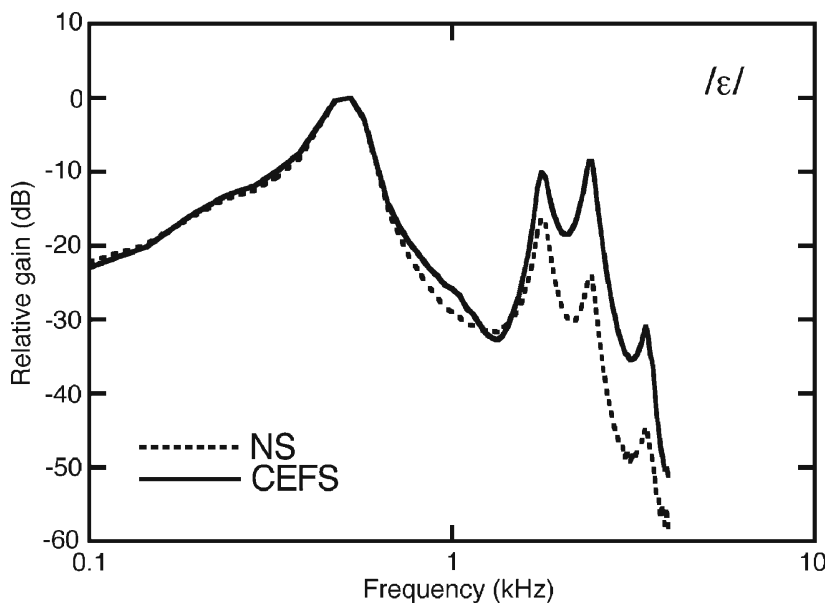

FIG. 6. Formant structure of the English vowel $/ \varepsilon /$. Relative to the naturally shaped (NS) vowel, the contrast-enhanced frequencyshaped (CEFS) vowel has more energy in its upper formants. frequency. The passband of the filter had a gain of $30 \mathrm{~dB}$. These parameters are based on stimuli that were used in previous electrophysiological studies of vowel representation with sensorineural hearing loss (Miller et al. 1999; Schilling et al. 1998).

\section{RESULTS}

The major findings of this study are organized around three experimental manipulations. Equal latency contours were derived by testing cats with the RT-matching paradigm. Loudness recruitment was evaluated by comparing RT measures under identical stimulus conditions before and after sound exposure. The effects of sound amplification on loudness recruitment were explored by comparing response latencies for NS and CEFS vowels.

\section{Equal latency contours}

The average equal latency contours of six cats are shown in Figure 7A. These plots were created by translating RTs to loudness levels in phons based on each subject's 1$\mathrm{kHz}$ criterion latencies. The data were then averaged across subjects and smoothed to duplicate the presentation of human data in Figure 7B (Suzuki and Takeshima 2004). The human contours were estimated from equations relating loudness to SPL that were derived from the combined results of 12 independent studies of loudness perception.

When differences in absolute sensitivity and audible frequency range are taken into consideration, there is good agreement between loudness data in cats and humans. The audibility curve of each species is indicated by the dashed line in each figure. The threshold estimates suggest that Liberty Lab cats are approximately $10 \mathrm{~dB}$ more sensitive than humans at $1 \mathrm{kHz}$. Consequently, in terms of sensation level, the 0-phon loudness level of cats should be compared with the 10-phon loudness level of humans.

The equal latency contours of cats and the equal loudness contours of humans are similarly influenced by sound level. At low levels, the contours approximate threshold estimates. At medium levels, they become closely spaced at low frequencies. These data suggest that both species experience a rapid growth of loudness at low frequencies.

The contours of cats and humans appear to diverge at high frequencies. Cats showed steep deceases in RT with increasing SPL, resulting in closely spaced equal latency contours. These data indicate rapid loudness growth. Humans showed a flattening of the loudness functions with equal spacing between contours, which indicates normal loudness growth. Attempts to obtain reliable loudness-matched RTs at $32 \mathrm{kHz}$ were not 

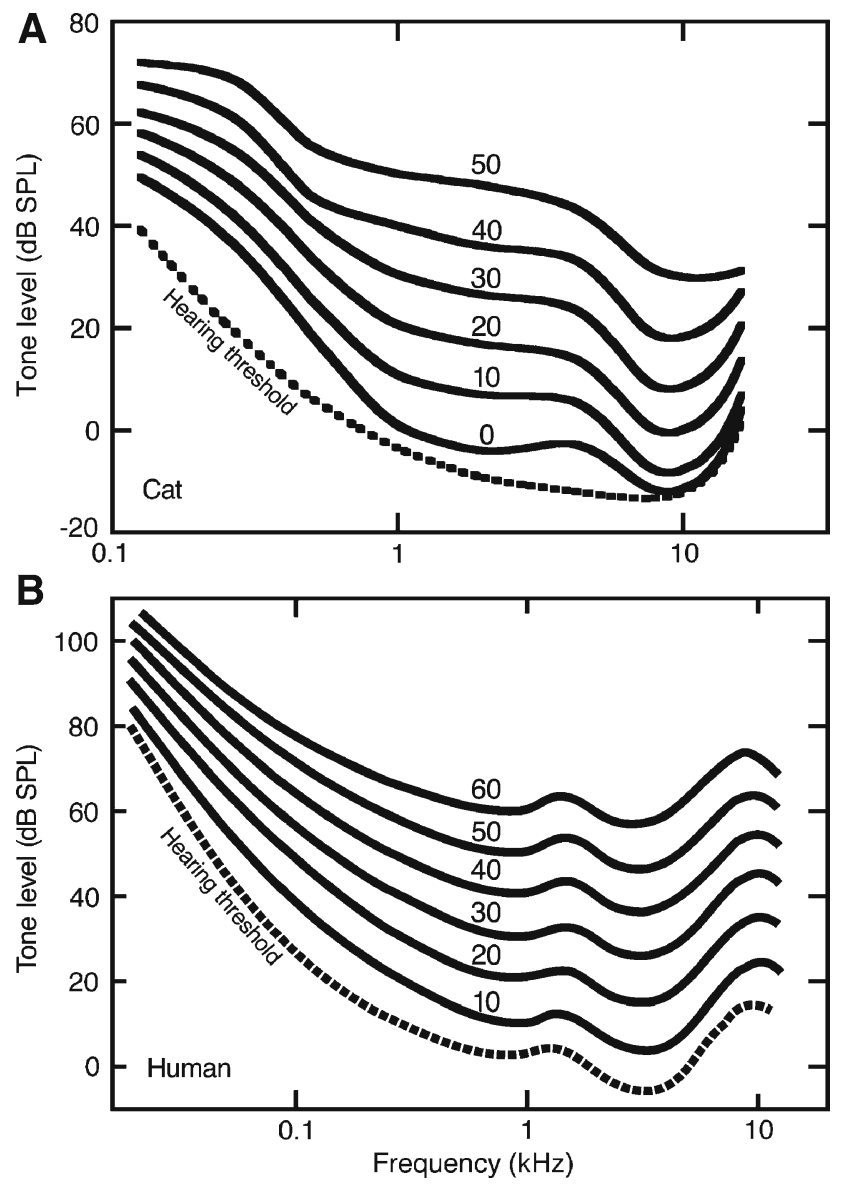

FIG. 7. Average equal latency contours for the six cats in the present study (A) and equal loudness contours estimated from human psychophysical studies (B). Numerical labels specify the loudness level in phons. Dashed lines indicate absolute thresholds. Threshold function for cats was derived by averaging the three data sources in Figure 5A. Human data are taken from Suzuki and Takeshima (2004).

successful in the present study because subjects showed large variations in RT measures. Whether the disparity reflects actual species differences, or an inadequate sampling of high-frequency hearing, remains unanswered.

\section{Growth of loudness after sound exposure}

An analysis of level-matched reaction times (LMRTs) reveals the effects of sound exposure on loudness perception. This metric is illustrated in Figure $8 \mathrm{~A}$ using representative data from cat Lu016. Each data point plots the median pre-exposure RT for a given frequency and SPL against the post-exposure RT for the same stimulus. In almost every instance, the data fall to the right of the unity line. The longer latencies of post-exposure responses imply that identical stimuli were perceived as less loud after sound exposure. Although the change in loudness was greatest near the frequency of sound exposure (Fig. 8B), the effect was pervasive.
Recruitment is defined as an abnormally rapid growth of loudness level with increasing sound level. In the context of RT-based measures, the phenomenon translates to an abnormal rate of decreasing RT. These effects can be inferred from the slopes of the LMRT functions in Figure 8A. When slopes are greater than unity, RTs decreased faster after exposure than before exposure. This outcome is the operational definition of recruitment in the present study. Although recruitment was observed across a wide range of frequencies at lower sound levels (Fig. 8A), the effect was most pronounced at the exposure frequency (Fig. 8B). Conversely, LMRT slopes approach unity at higher sound levels, suggesting that loudness growth remained normal at sound levels well above threshold.

The effects of level on loudness growth were analyzed by applying separate linear fits to contiguous data points at low and high levels of the LMRT functions. The breakpoint between the two fits was varied to produce the best fit to each dataset. The breakpoint point was included in both fits. Typical fits are illustrated in Figure 8B. A scatterplot comparing the slopes at all frequencies is presented in Figure 8C. The data show a strong tendency to fall to the right of the unity line, supporting the interpretation that the increased rate of loudness growth was confined to lower sound levels.

The analysis of LMRT slopes is extended to all cats in Figure 9. Distributions combining all frequencies are presented as boxplots in Figure 9A. Each box has vertical limits that correspond to the inter-quartile range (middle 50\%) of the two distributions and is subdivided at the median. Error bars mark scores falling within \pm 1.5 inter-quartile ranges. Outliers beyond these limits are plotted as individual data points. Median slopes were 2.0 and 1.0 at low and high levels, respectively. Non-parametric statistical testing indicated that the effect of level was statistically significant $(p<0.001$, paired sign test with two tails, implemented in MATLAB as signtest). Additional statistical testing confirmed that the post-exposure growth of loudness at high levels did not differ from pre-exposure values (slope $=1$, sign test with two tails, MATLAB signtest). The low-level slopes show good agreement with the rate-matching slopes of ventral cochlear nucleus (VCN) chopper units in soundexposed cats (1.73; Cai et al. 2009) and the median loudness balance slope from several studies of human recruitment (1.9; Miskolczy-Fodor 1960; Moore and Glasberg 2004; Moore et al. 1985; Stillman et al. 1993; Zeng and Turner 1991).

The effects of level on LMRT are broken down by frequency in Figure 9B and C. The inter-quartile range of low-level slopes falls above the unity line at every frequency (Fig. 9B). While these data suggest that recruitment was widespread after sound expo- 
A
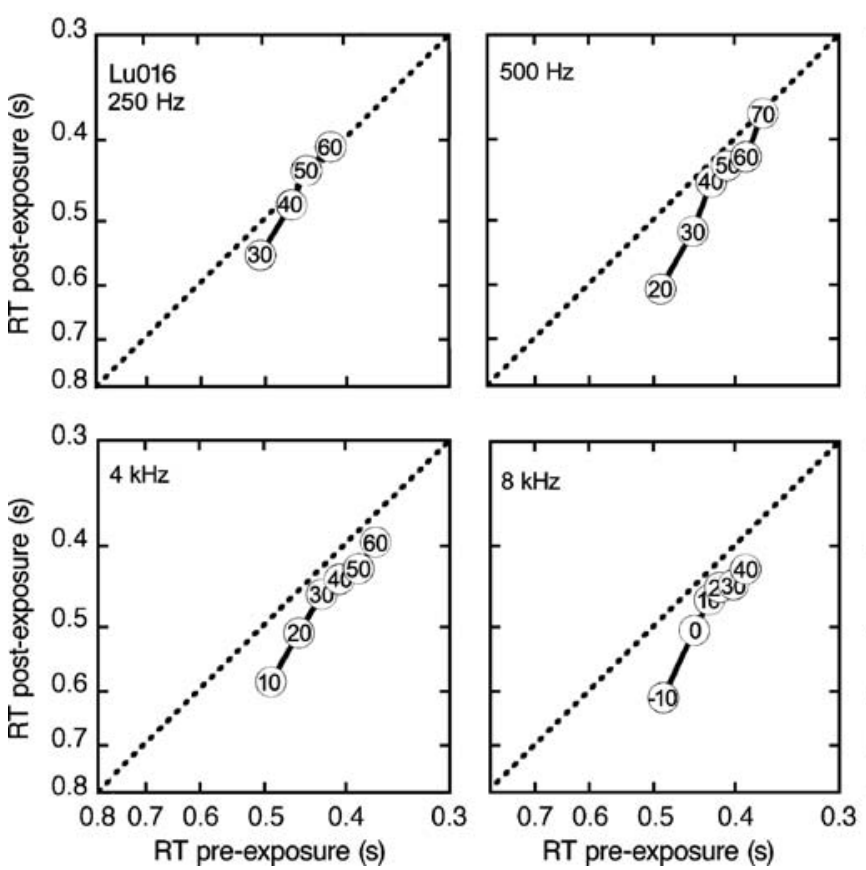

FIG. 8. Effects of sound exposure on RT functions. Results are shown for cat Lu016. A Each panel plots RTs at the same frequency and SPL before and after sound exposure. Numerical labels indicate SPL. Points falling to the right of the unity line suggest decreased loudness level after exposure. B The growth of loudness was estimated from the slopes of linear fits that were applied separately to low- and high-level data points. Representative fits are shown for

sure, the frequency of sound exposure $(2 \mathrm{kHz})$ displayed the steepest slope (most rapid growth of loudness). Conversely, the inter-quartile range of high-level slopes encompassed normal values at all frequencies. The high-level distributions also displayed their highest slopes at frequencies near the exposure frequency $(0.5-2 \mathrm{kHz})$.

Analysis of LMRT functions is the preferred method for evaluating recruitment in the present study because it allows the most complete presentation of pre- and postexposure RT data. A shortcoming of this approach is that the metric does not conform to the loudness-matching procedures that are typically used in human studies. Recruitment effects can be translated to phon loudness levels by matching post-exposure RTs to the $1-\mathrm{kHz}$ preexposure baselines of the same subject. This is the procedure that was used to calculate the equal latency functions in Figure 7A.

The calculation of post-exposure phon loudness levels is illustrated in Figure 10A using data from cat Lu016. This subject exhibited a pre-exposure RT of $0.506 \mathrm{~s}$ when tested with $1-\mathrm{kHz}$ tones at $10 \mathrm{~dB}$ SPL. The criterion RT was associated with an SPL of $24.5 \mathrm{~dB}$ when the cat was tested with $2-\mathrm{kHz}$ tones after sound exposure (arrow). Therefore, 24.5 dB SPL is assigned a loudness level of 10 phons. The
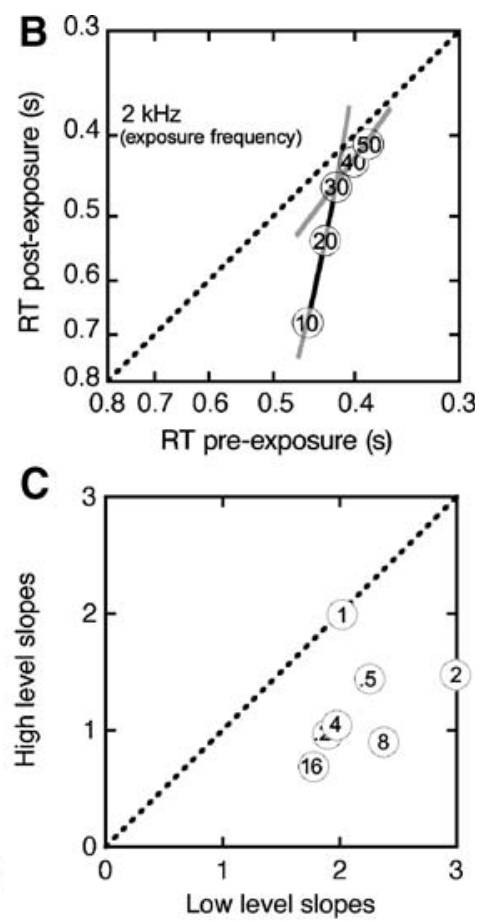

2-kHz data (gray lines). C Scatterplot of low- versus high-level slopes of the seven RT functions. Points falling to the right of the unity line have a higher slope (more rapid growth of loudness) at lower sound levels. Numerical labels indicate the tone frequencies that produced the data points. The low-level slope at the $2-\mathrm{kHz}$ exposure frequency (6.15) falls outside the upper limit of the $x$-axis and is plotted on the right $y$-axis.

procedure is repeated for RTs at 20-40 dB SPL to generate the growth of loudness function (GOLF) in Figure 10B.

The low-level data points in Figure 10B were fitted with a line to calculate the growth of loudness. The slope of the loudness-matching function was 1.7, which is lower than the results that were derived from the LMRT function (Fig. 9B). Inspection of the postexposure data in Figure 10A points out a critical limitation of the loudness-matching procedure that contributed to this discrepancy. A powerful recruitment effect is implied by the transition from very slow response latencies at low SPLs to normal pre-exposure values at intermediate SPLs. A substantial portion of this region of conspicuous loudness growth cannot be converted to phon measures because there are no pre-exposure RTs less than $0.506 \mathrm{~s}$. Consequently, the loudness-matching procedure estimates the growth of loudness at higher sound levels.

\section{Effects of amplification on loudness recruitment}

Previous electrophysiological studies have shown that the auditory nerve coding of vowel formant information is improved when sound-exposed cats are tested with contrast-enhanced frequency-shaped 
A

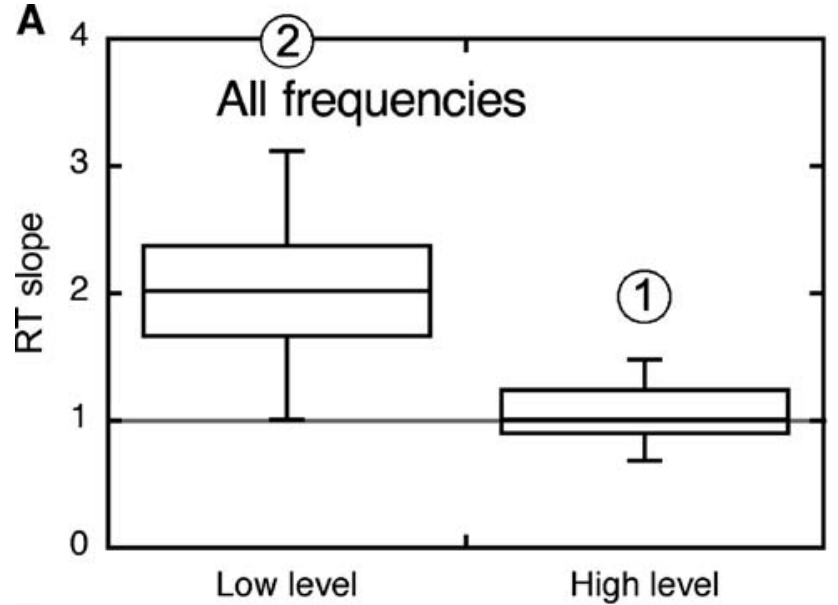

B

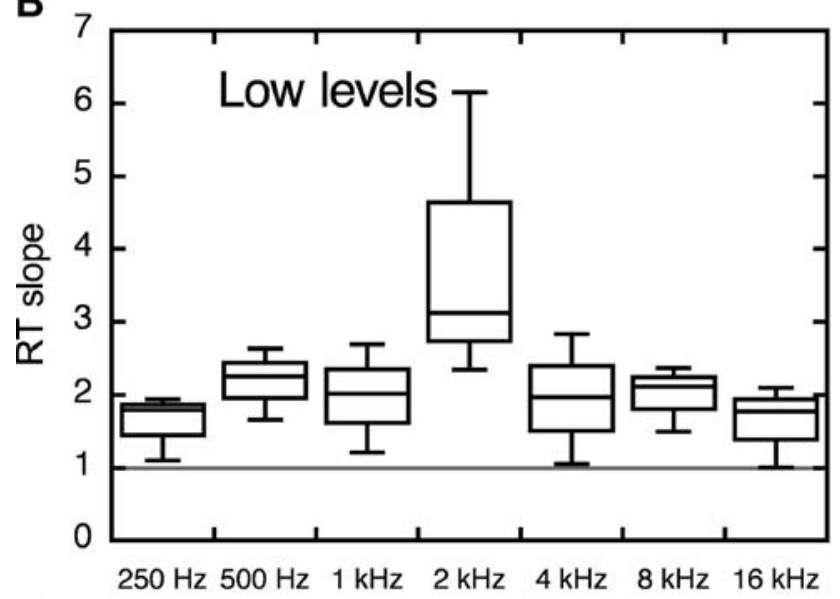

C

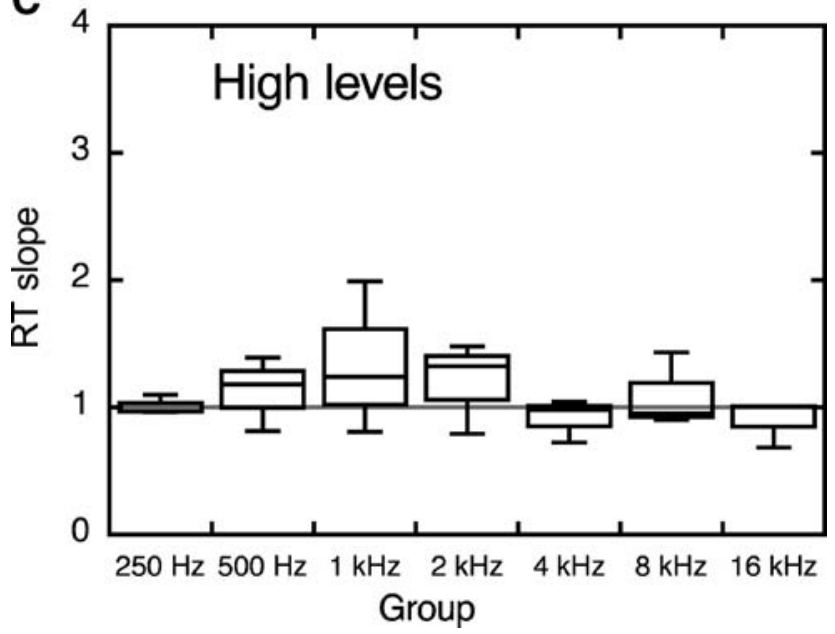

FIG. 9. Distributions of RT slopes for all cats. Methods for the calculation of slopes are illustrated in Figure 8. Conventions for boxplots are described in text. A Low- and high-level distributions collapsed across all frequencies. The difference between slopes is statistically significant $(p<0.001$, paired sign test). The average high level slope was not significantly different from 1 (sign test). The maximum range has been truncated at 4 to facilitate visual comparisons between the two datasets. The outlier among the lowlevel data is the 2-kHz slope of cat Lu016 (6.15), which is plotted at the upper limit of the $y$-axis. B, C Low- and high-level slopes separated by frequency. Note the expanded $y$-axis for low-level slopes.
(CEFS) vowels (Schilling et al. 1998; Miller et al. 1999). Our previous attempts to demonstrate superior behavioral discrimination with these stimuli have met with limited success because cats appeared to find the sounds aversive after exposure. The breakdown in behavioral performance was attributed to recruitment effects that were induced by the selective amplification of sound energy at formant frequencies near the site of acoustic trauma. The present study tested that hypothesis by assessing the loudness of naturally shaped (NS) and CEFS vowels with RT procedures.

The effects of sound exposure on vowel loudness are summarized in Figure 11, using data from two cats (Lu016 and Pe405). The LMRTs for the NS vowel are shown in Figure 11A and B. At low sound levels (slow RTs), the functions are skewed to fall to the right of the unity line, suggesting a decrease in loudness after exposure. A strong recruitment effect is indicated by
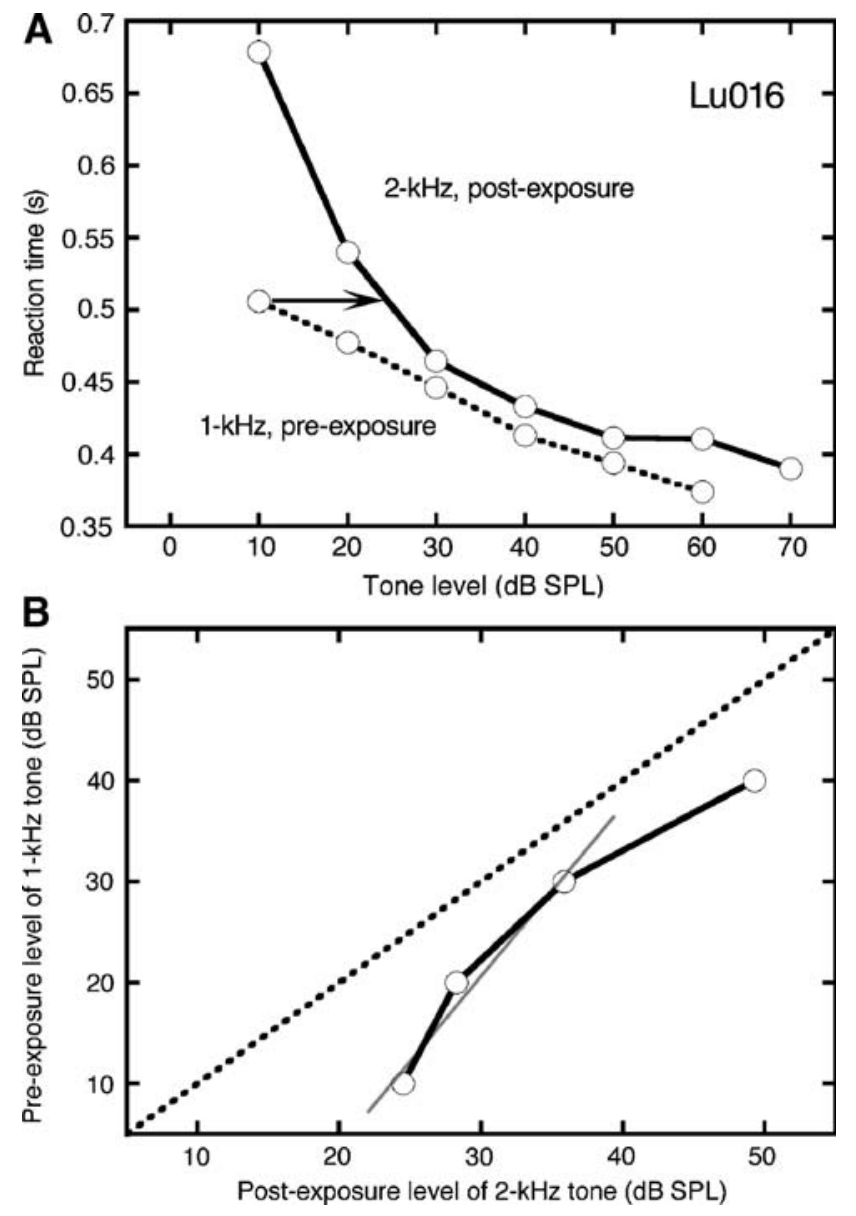

FIG. 10. Loudness-matching results for cat Lu016. A The relationship between tone level and RT at $1 \mathrm{kHz}$ before exposure and $2 \mathrm{kHz}$ after exposure. To elicit the RT of the $1-\mathrm{kHz}$ tone at $10 \mathrm{~dB} \mathrm{SPL}$, the 2$\mathrm{kHz}$ tone must be $24.5 \mathrm{~dB}$ SPL (arrow). B Growth of loudness function (GOLF) derived from the RTs in A. Recruitment is suggested by the rapid rise in loudness at low levels. A linear fit (gray line) to pre-exposure loudness levels of 10-30 dB produced a slope of 1.7. 
the steep slopes of the functions which converge on unity at higher levels. The LMRTs for the CEFS vowel are shown in Figure 11C and D. Although the low-level slopes for the CEFS vowel were somewhat steeper than those for the NS vowel, differences in the responses to the two vowels were subtle.
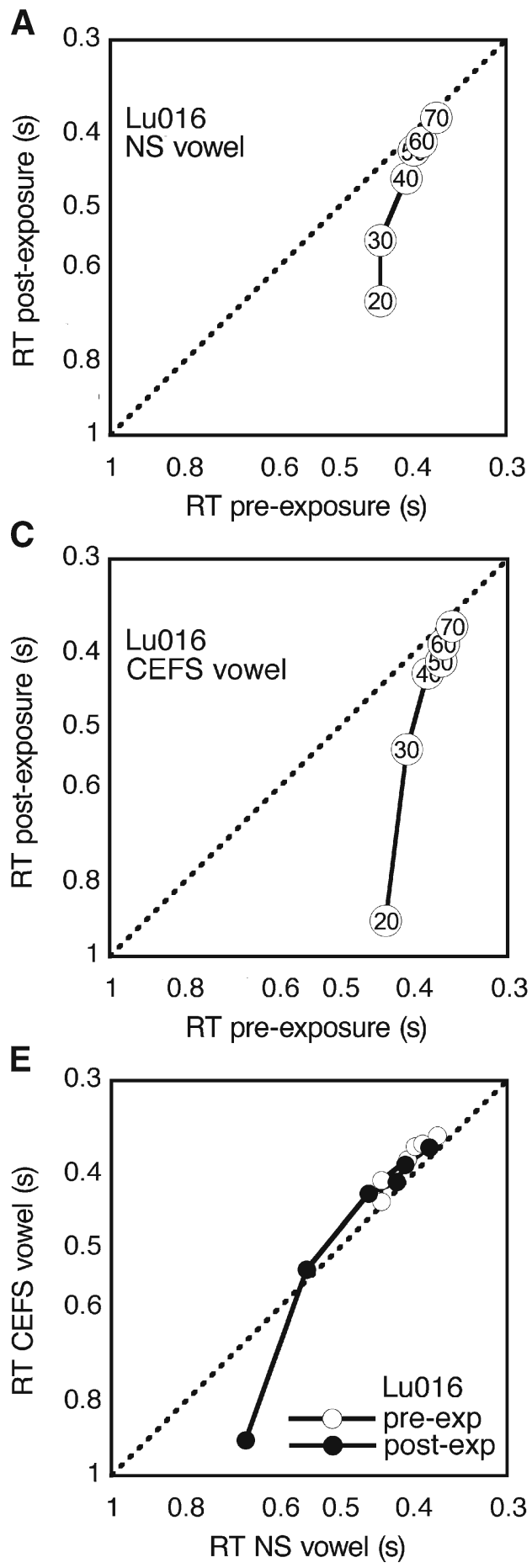

FIG. 11. Effects of sound exposure on RT for naturally shaped (NS) and contrast-enhanced frequency-shaped (CEFS) vowels. Results are shown for cats Lu016 and Pe405. A, B Pre-exposure versus postexposure RTs for the NS vowel. C, D Reaction times for the CEFS
A more direct comparison of the loudness of the two vowels is provided in Figure 11E and F, which plots the pre- and post-exposure RTs of the CEFS vowel against those for the NS vowel. Most points fall to the left of the unity line. Based on these measures, the CEFS vowel was perceived to be slightly louder when presented at the
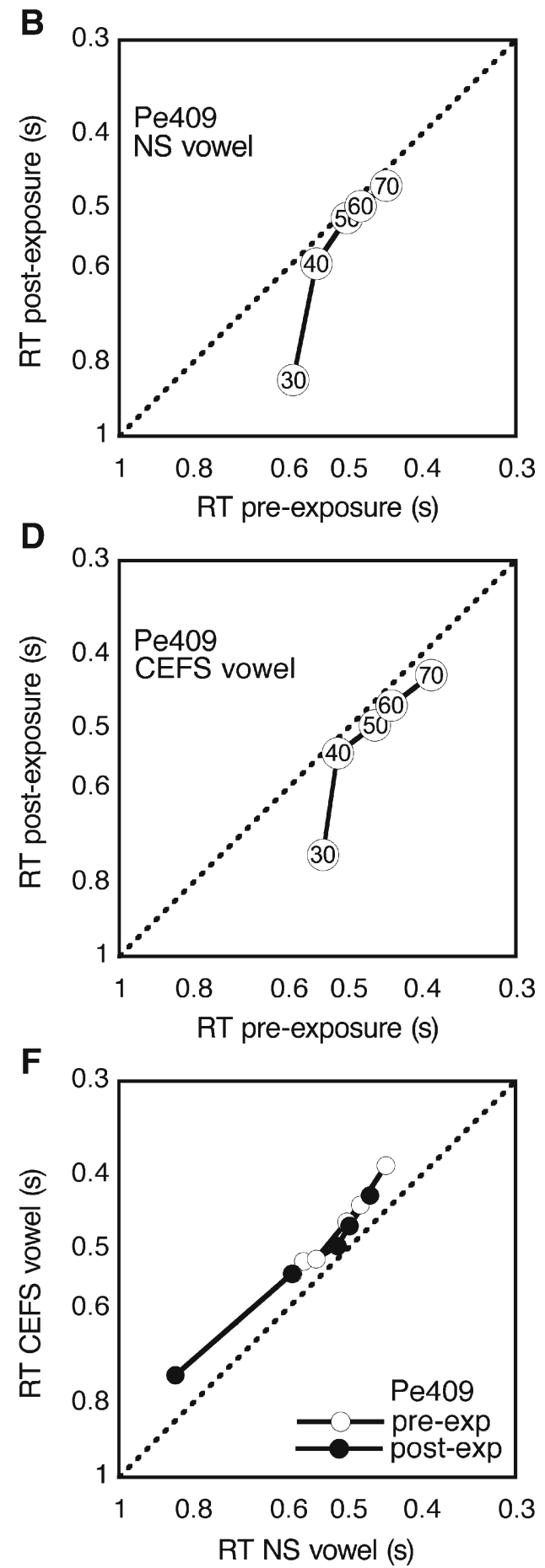

vowel. Plotting conventions are described in Figure 8. E, F Reaction times for CEFS versus NS vowels before and after exposure. Points falling along the unity line indicate similar loudness effects for the two spectral shapes. 
same sound level as the NS vowel. This effect is predicted by the shape of the cat's audibility curve (Fig. 5A), which displays more sensitive thresholds at frequencies above $0.5 \mathrm{kHz}$. Energy in this frequency region is enhanced by the high-pass amplification characteristics of the frequency-shaping procedure (Fig. 6). The slopes of the LMRT functions indicate that the growth of loudness was similar for the two vowels before and after exposure, although cat Lu016 showed slightly more recruitment for the CEFS vowel at low SPLs.

The low-level slopes for tone and vowel LMRT functions are compared in Figure 12. The two tone frequencies $(0.5$ and $2 \mathrm{kHz})$ were selected for this comparison because they fall near the formant frequencies of the vowels. The slopes for the NS and CEFS vowels clearly exceeded the slope of the $0.5-\mathrm{kHz}$ tone, and matched or surpassed the slope that was obtained with $2-\mathrm{kHz}$ tones. These tone frequencies evoked the most robust recruitment effects during experiments with pure tones (Fig. 9B). As predicted, relative to baseline measures with tonal stimuli, growth of loudness was accelerated by the increased bandwidth of vowel stimuli and further exacerbated by CEFS amplification.

\section{DISCUSSION}

Reaction time procedures reproduced the general features of human loudness perception in behaviorally trained cats with normal hearing (Fig. 7). After the cats were exposed to intense sound, the measures defined the broad range of sound frequencies (Fig. 9B) and constrained range of sound levels that evoked loudness recruitment (Fig. 9C). The largest recruitment effects

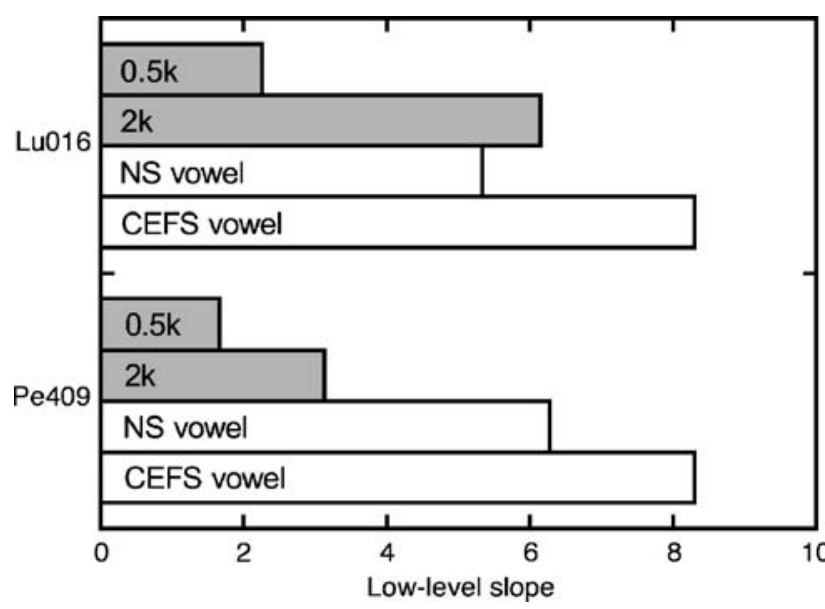

FIG. 12. The LMRT slopes of pure tones (gray fill) and vowels (white fill). Tone frequencies approximate the formant frequencies of the vowels. Results at low sound levels are shown for cats Lu016 and Pe409. A larger slope indicates stronger recruitment. for pure tones were observed at frequencies near the region of hearing loss. Synthetic speech generated a steeper growth of loudness than tones (Fig. 12). As was the case with tones, recruitment effects were exacerbated when spectral energy was shifted to the site of acoustic trauma by the selective amplification of higher formant frequencies.

Previous animal psychophysical studies of loudness perception

Reaction time has been used to evaluate loudness perception in animal models for several decades. The approach was first applied to non-human primates in studies by Stebbins and colleagues (Miller et al. 1969; Stebbins and Miller 1964), who characterized the relationship between RT and stimulus intensity (visual or auditory). These investigators reported equal latency contours that share many of the features of our present observations (Stebbins 1966), including a compressed range of latency/loudness measures at high frequencies (Fig. 7) and the extreme variation of RT near threshold (Fig. 3).

Pfingst et al. (1975) evaluated the reliability of RTbased measures in monkeys by comparing their performance to that of human observers. Both species were tested with the same RT-matching procedures, but human subjects were also tested with conventional loudness-matching paradigms. Changes in stimulus frequency and level elicited similar patterns of RT variations in both subject groups. In humans, equal latency contours closely followed the equal loudness contours that were derived with loudness-matching paradigms. As in the present study, a rapid growth of loudness was observed at low and high frequencies (Fig. 7).

Reaction time measures also have been used to characterize loudness perception in animal models of sensorineural hearing loss (Moody 1973; Pfingst et al. 1975; Pugh et al. 1979). The recruitment effects that were observed by Pfingst et al. are of particular relevance to the present study because a similar experimental design was used to compare the loudness perception of sound-exposed monkeys and hearing-impaired humans. Relative to normal listeners, the GOLFs of impaired subjects shifted by 20 $30 \mathrm{~dB}$ at threshold, rose steeply at intermediate SPLs, and compressed at high levels. The pre- and postexposure functions of our behavioral cats display the same relationships (Fig. 10B). Pfingst et al. correctly pointed out that compression may reflect a slowing of loudness growth or motor limitations of the behavioral subject. Of the two explanations, they advocated a perceptual basis for the effect because saturation changed with the frequency or bandwidth of the auditory stimulus. 
Reaction time studies of human loudness perception

Reaction time measures date back to early estimates of human loudness perception (Cattell 1886; Chocholle 1940). The assumption that equally loud stimuli generate equal RTs is not without controversy, however. While Chocholle observed equivalence, Kohfeld et al. (1981) did not. In the latter study, the inconsistency between loudness and RT was limited to lower loudness levels (20 phons) and may have been exacerbated by relatively sparse sampling of loudness matches and RT data. Additional studies have used the RT method to characterize the relationship between stimulus intensity and loudness in normal listeners (Marshall and Brandt 1980; Pins and Bonnet 1996), while others have pursued more complex perceptual phenomena such as loudness summation (Florentine et al. 2004) or adaptation (Arieh and Marks 2003). In general, where it is possible to make direct comparisons between RT and loudnessmatching procedures, results provide strong support for a close relationship.

Reaction time measures also have been used to evaluate loudness recruitment in hearing-impaired humans. Florentine et al. (2004) have presented RT data to support the existence of softness imperception (SI). This concept arises from psychoacoustic modeling of loudness summation in listeners with cochlear impairment. It is defined by greater than normal loudness at threshold when thresholds are elevated by hearing loss. Consequently, RT is expected to be faster at threshold in impaired listeners. In the present study, this prediction was not supported by results with pure tones (Fig. 8) or vowel stimuli (Fig. 11).

Sound exposure produced threshold shifts of approximately $20 \mathrm{~dB}$ in the present study. This hearing loss is comparable to experimentally induced manipulations in other animal studies of loudness recruitment, but it is much less than what was observed in Florentine's study of impaired humans. The thresholds of her impaired listeners ranged from 67 to $83 \mathrm{~dB}$ SPL at frequencies between 2 and $6 \mathrm{kHz}$, with an average threshold elevation of approximately $60 \mathrm{~dB}$.

Moore (2004) used a conventional loudness-matching paradigm to investigate loudness near threshold for humans with hearing loss. A unique feature of his approach was to utilize listeners with asymmetrical loss. Each subject provided a normal and an impaired ear for loudness matching. When a tone of low sensation level (high SPL) was presented to the impaired ear, it was matched to a tone of equal sensation level (low SPL) in the normal ear and therefore produced a normal (unity) growth of loudness. Moore's results, and our present findings, are inconsistent with the concept of softness imperception.
The unity growth of loudness that was reported by Moore (2004) was limited to sensation levels within 4 $10 \mathrm{~dB}$ of threshold. At higher sensation levels, he noted a steepening of the loudness-matching function that compares well with data in the present study. Because RT measures degrade near threshold (Fig. 3), it is not possible to evaluate loudness growth in hearing-impaired cats with sufficient reliability within the range of levels that predicts a unity slope. It is important to point out that our low-level slopes are derived from measures that include higher sensation levels.

\section{Physiological studies of loudness recruitment}

Physiological studies of loudness coding have focused on the relationship between discharge rates in the auditory nerve and sound pressure level. Two basic mechanisms have been hypothesized to explain the association between recruitment and cochlear impairment. Loudness growth may reflect the slope of ratelevel functions for individual auditory nerve fibers (Harrison 1981). Consequently, recruitment may arise because impaired basilar membrane mechanics increase the steepness of rate-level functions (Ruggero and Rich 1991). Alternatively, loudness may represent the total nerve response summed across all fibers (Relkin and Doucet 1997). In this case, more fibers may be excited in the recruiting ear because of a loss of mechanical tuning (Evans 1975; Kiang et al. 1970), or a compressed range of thresholds (Moore et al. 1985; Ngan and May 2001; Zeng and Turner 1991).

Heinz et al. (2005) evaluated these hypotheses in the auditory nerve of hearing-impaired cats that were treated with identical methods of sound exposure. The slopes of rate-level functions were widely scattered but not significantly different for cats with mild and moderate hearing loss for neither subject group did slopes differ significantly from those for normal controls. There also was no significant difference in the total rates shown by normal and impaired populations of auditory nerve fibers. Given the broad range of frequencies that elicited recruitment in the present study (Fig. 9B), and the inconsistencies between auditory nerve discharge rates and psychophysical assessments, it is likely that central mechanisms contribute to the abnormal perception of loudness.

Several physiological studies have used auditory evoked potentials (AEPs) to evaluate the effects of hearing loss on response magnitude in the central auditory system. After sound exposure, AEPs in the inferior colliculus show steeper slopes and greater maximum amplitudes (Salvi et al. 1990). A similar enhancement is seen in auditory cortex (Qiu et al. 2000; Syka et al. 1994). Recent fMRI measures extend those observations to hearing-impaired humans (Langers et al. 2007). 
Electrophysiological studies have shown that sound exposure may lead to an expanded representation of the cortical isofrequency laminae surrounding the site of trauma (Robertson and Irvine 1989). Although this reorganization is usually demonstrated in animals with dead zones (i.e., complete hearing loss over a limited frequency range), significant changes in cortical frequency maps have been observed with only $40 \mathrm{~dB}$ of loss (Norena and Eggermont 2005). Low sound levels may exert the perceptual impact of high sound levels after reorganization because they are correlated with the responses of abnormally large neural populations.

The increases in response magnitude that alter loudness coding at high levels of central auditory processing may reflect changes in local inhibition or abnormal inputs from lower processing centers (Potashner et al. 2000; Willott et al. 1997). Single-unit studies of the VCN suggest that rate-level functions steepen following sound exposure because of substantial increases in maximum rates (Cai et al. 2009). This potential correlate of recruitment is restricted to chopper neurons, which show an average slope of 1.7. These findings are in good agreement with psychophysical results in the present study (Fig. 9A). T-stellate neurons, the anatomical counterpart of the chopper response class, provide a major ascending projection to the contralateral inferior colliculus (Rhode et al. 1983) and therefore may contribute to the abnormal AEPs that are recorded in humans who experience loudness recruitment.

Relative to VCN primary-like neurons, the discharge rates of chopper units display an extended dynamic range under quiet conditions and in the presence of background noise (May et al. 1998; May and Sachs 1992). Models of the chopper neuron attribute these adaptive properties to highly convergent inputs from the auditory nerve and a gain selection mechanism that is controlled by local inhibition (Lai et al. 1994). The inhibition is suspected to arise from glycinergic D-stellate neurons that also reside in the VCN (Doucet and Ryugo 2006; Ferragamo et al. 1998). Tract-tracing studies have identified these large multipolar cells as the target of collateral projections from the medial olivocochlear system (Benson and Brown 1990). This descending pathway has been proposed as a feedback system for attenuating cochlear amplification at high sound pressure levels and restoring the lost gain by disinhibiting the chopper response. It is intriguing to speculate that a disruption of this pathway may contribute to loudness recruitment.

\section{ACKNOWLEDGMENTS}

This research was funded by NIDCD grants R01 DC000109 and P30 DC05211. Eric Young and members of his laboratory contributed greatly to the conceptual design of recruitment experiments. In particular, the authors thank Michael Heinz and Diana Ma for their assistance with sound exposure. Roger Miller synthesized vowel stimuli. Denise Brown supervised animal husbandry.

\section{REFERENCES}

ARIEH Y, Marks LE. Recalibrating the auditory system: a speedaccuracy analysis of intensity perception. J. Exp. Psychol. Hum. Percept. Perform. 29:523-536, 2003.

Benson TE, BRown MC. Synapses formed by olivocochlear axon branches in the mouse cochlear nucleus. J. Comp. Neurol. 295:52-70, 1990.

CAI S, Ma WL, Young ED. Encoding intensity in ventral cochlear nucleus following acoustic trauma: implications for loudness recruitment. J. Assoc. Res. Otolaryngol. 2009 (in press).

Cattell JM. The influence of the intensity of the stimulus on the length of the reaction time. Brain 8:512-515, 1886.

Chocholle R. Variation des temps de réaction auditifs en fonction de l' intensité à diverses fréquences. L' Année Psychologique 41:65-124, 1940.

Davis H, Goodman AC. Subtractive hearing loss, loudness recruitment and decruitment. Ann. Otol. Rhinol. Laryngol. 75:87-94, 1966.

Doucet JR, Ryugo DK. Structural and functional classes of multipolar cells in the ventral cochlear nucleus. Anat. Rec. A Discov. Mol. Cell. Evol. Biol. 288:331-344, 2006.

Ehret G, Merzenich MM. Neuronal discharge rate is unsuitable for encoding sound intensity at the inferior-colliculus level. Hear. Res. 35:1-7, 1988.

Evans EF. The sharpening of cochlear frequency selectivity in the normal and abnormal cochlea. Audiology 14:419-442, 1975.

Evans EF. Peripheral auditory processing in normal and abnormal ears: physiological considerations for attempts to compensate for auditory deficits by acoustic and electrical prostheses. Scand. Audiol. Suppl. 6:9-47, 1978.

FAY RR. Hearing in Vertebrates: A Psychophysics Databook. Winnetka, IL, Hill-Fay, 1995.

Ferragamo MJ, Golding NL, Oertel D. Synaptic inputs to stellate cells in the ventral cochlear nucleus. J. Neurophysiol. 79:51-63, 1998.

Fletcher H, Munson WA. Loudness, its definition, measurement, and calculation. J. Acoust. Soc. Am. 5:82-108, 1933.

Florentine M, Buus S, Rosenberg M. Reaction-time data support the existence of softness imperception in cochlear hearing loss. In: Pressnitzer D, de Cheveigné A, McAdams S, Collet L (eds) Auditory Signal Processing: Physiology, Psychoacoustics, and Models. New York, Springer, 2004.

Green DM. Psychoacoustics and detection theory. J. Acoust. Soc. Am. 31:1189-1202, 1960.

HARRISON RV. Rate-versus-intensity functions and related AP responses in normal and pathological guinea pig and human cochleas. J. Acoust. Soc. Am. 70:1036-1044, 1981.

Heinz MG, Young ED. Response growth with sound level in auditorynerve fibers after noise-induced hearing loss. J. Neurophysiol. 91:784-795, 2004.

Heinz MG, Issa JB, Young ED. Auditory-nerve rate responses are inconsistent with common hypotheses for the neural correlates of loudness recruitment. J. Assoc. Res. Otolaryngol. 6:91-105, 2005.

Kiang NYS, Moxon EC, Levine RA. Auditory-nerve activity in cats with normal and abnormal cochleas. In: Wolstenholme GEW, Knight T (eds) Sensorineural Hearing Loss. London, Churchill, pp. 241-273, 1970.

KLatT DH, KLatT LC. Analysis, synthesis, and perception of voice quality variations among female and male talkers. J. Acoust. Soc. Am. 87:820-857, 1990. 
Kohfeld DL, Santee JL, Wallace ND. Loudness and reaction time: I. Percept. Psychophys. 29:535-549, 1981.

LAI YC, Winslow RL, SACHS MB. A model of selective processing of auditory-nerve inputs by stellate cells of the antero-ventral cochlear nucleus. J. Comput. Neurosci. 1:167-194, 1994.

Langers DR, van Dijk P, Schoenmaker ES, Backes WH. fMRI activation in relation to sound intensity and loudness. Neuroimage 35:709-718, 2007.

Maison SF, Liberman MC. Predicting vulnerability to acoustic injury with a noninvasive assay of olivocochlear reflex strength. J. Neurosci. 20:4701-4707, 2000.

Marshall L, Brandt JF. The relationship between loudness and reaction time in normal hearing listeners. Acta. Otolaryngol. 90:244-249, 1980.

MAY BJ, SACHS MB. Dynamic range of neural rate responses in the ventral cochlear nucleus of awake cats. J. Neurophysiol. 68:1589-1602, 1992.

May BJ, Prell GS, SAchs MB. Vowel representations in the ventral cochlear nucleus of the cat: effects of level, background noise, and behavioral state. J. Neurophysiol. 79:1755-1767, 1998.

Miller JM, Moody DB, StebBins WC. Evoked potentials and auditory reaction time in monkeys. Science 163:592-594, 1969.

Miller RL, Schilling JR, Franck KR, Young ED. Effects of acoustic trauma on the representation of the vowel "eh" in cat auditory nerve fibers. J. Acoust. Soc. Am. 101:3602-3616, 1997.

Miller RL, Calhoun BM, Young ED. Contrast enhancement improves the representation of $/ \varepsilon /$-like vowels in the hearing-impaired auditory nerve. J. Acoust. Soc. Am. 106:2693-2708, 1999.

MiskolczYFodor F. Relationship between loudness and duration of tonal pulses. III. Response in cases of abnormal loudness function. J. Acoust. Soc. Am. 32:486-492, 1960.

Moody DB. Behavioral studies of noise-induced hearing loss in primates: loudness recruitment. Adv. Otorhinolaryngol. 20:82-101, 1973.

Moore BCJ. Testing the concept of softness imperception: loudness near threshold for hearing-impaired ears. J. Acoust. Soc. Am. 115:3103-3111, 2004.

Moore BCJ, GLASBerg BR. A revised model of loudness perception applied to cochlear hearing loss. Hear. Res. 188:70-88, 2004.

Moore BCJ, Glasberg BR, Hess RF, Birchall JP. Effects of flanking noise bands on the rate of growth of loudness of tones in normal and recruiting ears. J. Acoust. Soc. Am. 77:1505-1513, 1985.

NGAN EM, MAY BJ. Relationship between the auditory brainstem response and auditory nerve thresholds in cats with hearing loss. Hear. Res. 156:44-52, 2001.

Norena AJ, Eggermont JJ. Enriched acoustic environment after noise trauma reduces hearing loss and prevents cortical map reorganization. J. Neurosci. 25:699-705, 2005.

Palmer AR, Evans EF. Intensity coding in the auditory periphery of the cat: responses of cochlear nerve and cochlear nucleus neurons to signals in the presence of bandstop masking noise. Hear. Res. 7:305-323, 1982.

Pfingst Be, Hienz R, Kimm J, Miller J. Reaction-time procedure for measurement of hearing. I. Suprathreshold functions. J. Acoust. Soc. Am. 57:421-430, 1975.

Pins D, Bonnet C. On the relation between stimulus intensity and processing time: Pieron's law and choice reaction time. Percept. Psychophys. 58:390-400, 1996.
Plack CJ, Carlyon RP. Loudness perception and intensity coding. In: Moore BCJ (ed) Hearing. San Diego, CA, Academic, pp. 123$160,1995$.

Potashner SJ, Suneja SK, Benson CG. Altered glycinergic synaptic activities in guinea pig brain stem auditory nuclei after unilateral cochlear ablation. Hear. Res. 147:125-136, 2000.

Pugh JE, Jr, Moody DB, Anderson DJ. Electrocochleography and experimentally induced loudness recruitment. Arch. Otorhinolaryngol. 224:241-255, 1979.

Qiu C, Salvi R, Ding D, Burkard R. Inner hair cell loss leads to enhanced response amplitudes in auditory cortex of unanesthetized chinchillas: evidence for increased system gain. Hear. Res. 139:153-171, 2000.

Relkin EM, Doucet JR. Is loudness simply proportional to the auditory nerve spike count? J. Acoust. Soc. Am. 101:2735-2740, 1997.

Rhode WS, Oertel D, Smith PH. Physiological response properties of cells labeled intracellularly with horseradish peroxidase in cat ventral cochlear nucleus. J. Comp. Neurol. 213:448-463, 1983.

Robertson D, IRvine DR. Plasticity of frequency organization in auditory cortex of guinea pigs with partial unilateral deafness. J. Comp. Neurol. 282:456-471, 1989.

Ruggero MA, Rich NC. Furosemide alters organ of corti mechanics: evidence for feedback of outer hair cells upon the basilar membrane. J. Neurosci. 11:1057-1067, 1991.

Salvi RJ, Saunders SS, Gratton MA, Arehole S, Powers N. Enhanced evoked response amplitudes in the inferior colliculus of the chinchilla following acoustic trauma. Hear. Res. 50:245-257, 1990.

Schilling JR, Miller RL, SAchs MB, Young ED. Frequency-shaped amplification changes the neural representation of speech with noise-induced hearing loss. Hear. Res. 117:57-70, 1998.

Stebbins WC. Auditory reaction time and the derivation of equal loudness contours for the monkey. J. Exp. Anal. Behav. 9:135142, 1966.

Stebbins WC, Miller JM. Reaction time as a function of stimulus intensity for the monkey. J. Exp. Anal. Behav. 7:309-312, 1964.

Stevens SS, Guirao M. Subjective scaling of length and area and the matching of length to loudness and brightness. J. Exp. Psychol. 66:177-186, 1963.

Stillman JA, Zwislocki JJ, Zhang M, Cefaratti LK. Intensity justnoticeable differences at equal-loudness levels in normal and pathological ears. J. Acoust. Soc. Am. 93:425-434, 1993.

Suzuki Y, TAKeshima H. Equal-loudness-level contours for pure tones. J. Acoust. Soc. Am. 116:918-933, 2004.

Syka J, Rybalko N, Popelar J. Enhancement of the auditory cortex evoked responses in awake guinea pigs after noise exposure. Hear. Res. 78:158-168, 1994.

Wagner E, Florentine M, Buus S, McCormack J. Spectral loudness summation and simple reaction time. J. Acoust. Soc. Am. 116:1681-1686, 2004.

Willott JF, Milbrandt JC, Bross LS, Caspary DM. Glycine immunoreactivity and receptor binding in the cochlear nucleus of C57BL/6J and CBA/CaJ mice: effects of cochlear impairment and aging. J. Comp. Neurol. 385:405-414, 1997.

Zeng FG, Turner CW. Binaural loudness matches in unilaterally impaired listeners. Q. J. Exp. Psychol. A 43:565-583, 1991. 